\title{
Use of Early Extra-Corporeal Membrane Oxygenation (ECMO) for Severe Refractory Status Asthmaticus
}

\author{
Catherina L Chang ${ }^{\mathrm{a}}$, Deborah H Yates ${ }^{\mathrm{a}, \mathrm{b}}$
}

\begin{abstract}
Emerging evidence suggests that extra-corporeal membrane oxygenation (ECMO) improves survival in adults with reversible respiratory failure compared to conventional ventilation. Refractory status asthmaticus is an uncommon indication for ECMO. We present a case of near fatal status asthmaticus not responsive to conventional treatment and ventilation, in whom early use of ECMO resulted in a positive outcome. This case illustrates ECMO as a useful bridging therapy in this group of patients.
\end{abstract}

Keywords: Asthma; Extra-corporeal membranous oxygenation; Extra-corporeal life support; Status asthmaticus; Respiratory failure

\section{Introduction}

Despite improvements in asthma therapy, hospitalisation for exacerbation of asthma remains common and mortality after admission to critical care is substantial [1, 2]. Mechanical ventilation for respiratory failure due to asthma is a life saving intervention and is currently the treatment of choice [3]. A recent multi-center trial has reported improved survival in adults with reversible acute respiratory failure treated with extra-corporeal membrane oxygenation (ECMO) compared with conventional ventilation $[4,5]$. Status asthmaticus is a suitable indication for ECMO as it is potentially reversible and generally occurs in otherwise healthy individuals.

We report a case of successful early use of ECMO to

Manuscript accepted for publication April 4, 2011

${ }^{a}$ Department of Thoracic Medicine, St Vincent's Hospital, Sydney, Australia

${ }^{\mathrm{b} C o r r e s p o n d i n g ~ a u t h o r: ~ D e b o r a h ~ H ~ Y a t e s, ~ X a v i e r ~ L e v e l ~ 4, ~ V i c t o r i a ~ S t, ~}$ Darlinghurst, NSW 2010, Australia. Email: Deborahy88@hotmail.com

doi: $10.4021 / \mathrm{jmc} 204 \mathrm{w}$ treat respiratory failure due to status asthmaticus that was unresponsive to conventional ventilation. We believe this is the first case report of ECMO used for adult status asthmaticus in Australasia.

\section{Case Report}

A 37-year-old Korean man presented to the Emergency Department with increasing dyspnoea over the preceding 24 hours which was refractory to inhaled salbutamol. He had been diagnosed with asthma at the age of 23 and had previously required mechanical ventilation for exacerbation of asthma. He had discontinued all of his regular asthma medications 6 weeks prior to hospital presentation because of difficulties in obtaining these in Australia and cost considerations. He had experienced symptoms of lower respiratory tract infection with a purulent productive cough, wheeze, nocturnal awakening and breathlessness over the previous week.

On presentation he was severely dyspnoeic and cyanotic, with a respiratory rate of $50 / \mathrm{min}$, arterial oxygen saturation of $<75 \%$ on room air, blood pressure of $200 / 100 \mathrm{mmHg}$ and heart rate of $123 / \mathrm{min}$. Initial venous blood gas values on $15 \mathrm{~L} / \mathrm{min}$ oxygen via non-rebreather mask were: $\mathrm{pH} 7.13$, pCO $84 \mathrm{mmHg}, \mathrm{pO}_{2} 61 \mathrm{mmHg}, \mathrm{HCO}_{3}-26 \mathrm{mmol} / \mathrm{L}$. He was initially treated with oxygen therapy and non-invasive ventilatory support at an inspiratory pressure of $10 \mathrm{cmH}_{2} \mathrm{O}$ and expiratory pressure of $5 \mathrm{cmH}_{2} \mathrm{O}$, continuous nebulised salbutamol, and intravenous administration of hydrocortisone 200 $\mathrm{mg}$, magnesium sulphate $5 \mathrm{~g} \times 2$, ceftriaxone $1 \mathrm{~g}$ and azithromycin $500 \mathrm{mg}$. He continued to deteriorate over the course of the next 20 minutes with a reduced level of consciousness (Glasgow coma score decreased from 15 to 11/15) and decreasing respiratory effort. Repeat arterial blood gas revealed increasingly severe respiratory acidosis: $\mathrm{pH} 7.06$, $\mathrm{pCO}_{2} 100 \mathrm{mmHg}, \mathrm{pO}_{2} 591 \mathrm{mmHg}, \mathrm{HCO}_{3}-25 \mathrm{mmol} / \mathrm{L}$. He was intubated, and admitted to the intensive care unit after commencement of mechanical ventilation.

A subsequent chest radiograph revealed hyperinflation and evolving bilateral infective changes associated with a peripheral leucocytosis $\left(17.9 \times 10^{9} / \mathrm{L}\right)$, neutrophilia $(14.1 \times$ 
$10^{9} / \mathrm{L}$ ) and raised inflammatory markers (C-reactive protein $25.4 \mathrm{mg} / \mathrm{L}$ ). Blood, sputum and broncho-alveolar lavage cultures were negative and empiric anti-microbial cover (ceftriaxone and azithromycin) were continued. Adjunctive treatments including nebulised bronchodilators, intravenous corticosteroid, magnesium sulphate and theophylline were also continued.

Synchronised intermittent mandatory pressure control ventilation was initiated at an inspiratory fraction of oxygen $\left(\mathrm{FiO}_{2}\right)$ of 1.0 and peak inspiratory pressure (PIP) of $22-33$ $\mathrm{cmH}_{2} \mathrm{O}$. Positive end-expiratory pressure (PEEP) was maintained at $3-5 \mathrm{cmH}_{2} \mathrm{O}$ with tidal volumes of $300-360 \mathrm{~mL}$. However, hypercapneac respiratory failure persisted with no improvement in the patient's blood gases. Repeat arterial blood gas values at 22 hours post intubation and ventilation were: $\mathrm{pH}$ 7.06, $\mathrm{pCO}_{2} 107 \mathrm{mmHg}, \mathrm{pO}_{2} 105 \mathrm{mmHg}$, $\mathrm{HCO}_{3}-29 \mathrm{mmol} / \mathrm{L}$. A decision to commence veno-venous extra-corporeal membranous oxygenation was made by the intensive care and respiratory teams. This was performed via bi-femoral venous cannulation with an initial femoral-atrial flow of $3.1 \mathrm{~L} / \mathrm{min}$. Following the establishment of ECMO the blood gases rapidly normalised. Values at 90 minutes after starting ECMO were: $\mathrm{pH} 7.36, \mathrm{pCO}_{2} 50 \mathrm{mmHg}, \mathrm{pO}_{2} 86$ $\mathrm{mmHg}, \mathrm{HCO}_{3}-28 \mathrm{mmol} / \mathrm{L}$. Heparin was infused to maintain activated clotting time at 50 - 75 seconds. Apart from a right femoral puncture site hematoma, there was no complication associated with ECMO. Adequate gas exchange was achieved with pressure control ventilation at PIP of 22 $\mathrm{cmH}_{2} \mathrm{O}$ and $\mathrm{FiO}_{2} 0.4$ by day 4 and the patient was weaned off ECMO by gradual flow reduction by day 5 . Total ICU stay was 10 days.

\section{Discussion}

Emerging evidence suggests that ECMO improves survival in adults with reversible respiratory failure compared to conventional ventilation $[4,5]$. ECMO is the most common circulatory assist device in pediatrics patients, and is frequently used in this context for severe respiratory failure. Refractory status asthmaticus remains an uncommon indication for ECMO. The existing published literature on ECMO in adult refractory status asthmaticus is limited to a handful of case reports [6-10] and one registry review [11]. The recently published review of the international Extracorporeal Life Support Organization Registry suggests better outcomes in this patient subgroup [11]. The review contained 1,257 adults with respiratory failure treated with extracorporeal life support of which only $24(2 \%)$ had status asthmaticus as the primary indication. Survival to hospital discharge was $51 \%$ for the entire cohort and $83 \%$ for the asthmatic group and this survival benefit remained after adjustment for potential confounders such as age and severity of respiratory failure. Possibly, this is because most patients with status asthmati- cus are usually young and healthy otherwise. It is interesting to note that most anecdotal case reports describing the use of ECMO for status asthmaticus do so in the setting of impending cardiorespiratory collapse from ventilatory failure. Given the potential complications of continued attempts at failing or marginal ventilation in these patients such as volutrauma, barotrauma and high flow oxygen toxicity and the fact that respiratory compromise from status asthmaticus is often completely reversible, the case for early ECMO as bridging therapy is worth considering. Prolonged ECMO is however associated with several complications, including hemorrhage and infection.

At present there are no evidence-based guidelines as to when to commence ECMO for status asthmaticus. Kukita et al have suggested a management algorithm which includes ECMO in the setting of hypoxemia, $\mathrm{pH}<7.2, \mathrm{PCO}_{2}>100$ $\mathrm{mmHg}$ or in the face of life threatening complications due to ventilation such as hypotension or barotraumas [7]. In addition to this, we believe consideration should also be given to commencing ECMO if there is rapid deterioration despite optimal ventilation or lack of improvement with optimal ventilation after a reasonable trial period.

With the increasing availability of ECMO, prospective clinical trials are urgently needed to allow the development of appropriate guidelines in this patient population. The indications suggested here may be a starting point for the development of relevant trials.

\section{Acknowledgement}

The authors wish to thank Dr. Scott Robinson for contribution to the manuscript.

\section{References}

1. Krishnan V, Diette GB, Rand CS, Bilderback AL, Merriman B, Hansel NN, Krishnan JA. Mortality in patients hospitalized for asthma exacerbations in the United States. Am J Respir Crit Care Med 2006;174(6):633638.

2. Watson L, Turk F, Rabe KF. Burden of asthma in the hospital setting: an Australian analysis. Int J Clin Pract 2007;61(11):1884-1888.

3. British Guideline on the Management of Asthma. Tho$\operatorname{rax}$ 2008;63 Suppl 4:iv1-121.

4. Peek GJ, Clemens F, Elbourne D, Firmin R, Hardy P, Hibbert C, Killer H, et al. CESAR: conventional ventilatory support vs extracorporeal membrane oxygenation for severe adult respiratory failure. BMC Health Serv Res 2006;6:163.

5. Peek GJ, Elbourne D, Mugford M, Tiruvoipati R, Wilson A, Allen E, et al. Randomised controlled trial and 
parallel economic evaluation of conventional ventilatory support versus extracorporeal membrane oxygenation for severe adult respiratory failure (CESAR). Health Technol Assess 2010;14(35).

6. Shapiro MB, Kleaveland AC, Bartlett RH. Extracorporeal life support for status asthmaticus. Chest 1993;103(6):1651-1654.

7. Kukita I, Okamoto K, Sato T, Shibata Y, Taki K, Kurose $\mathrm{M}$, Terasaki H, et al. Emergency extracorporeal life support for patients with near-fatal status asthmaticus. Am J Emerg Med 1997;15(6):566-569.

8. Mikkelsen ME, Pugh ME, Hansen-Flaschen JH, Woo YJ, Sager JS. Emergency extracorporeal life sup- port for asphyxic status asthmaticus. Respir Care 2007;52(11):1525-1529.

9. Sakai M, Ohteki H, Doi K, Narita Y. Clinical use of extracorporeal lung assist for a patient in status asthmaticus. Ann Thorac Surg 1996;62(3):885-887.

10. Leiba A, Bar-Yosef S, Bar-Dayan Y, Weiss Y, Segal E, Paret G, Vardi A. Early administration of extracorporeal life support for near fatal asthma. Isr Med Assoc J 2003;5(8):600-602.

11. Mikkelsen ME, Woo YJ, Sager JS, Fuchs BD, Christie JD. Outcomes using extracorporeal life support for adult respiratory failure due to status asthmaticus. ASAIO J 2009;55(1):47-52. 